\title{
Reflexiones bioéticas. Comité Hospitalario de Bioética. Presentación de libro
}

\author{
Bioetical reflections. Hospital Bioethics Committee. \\ Book release
}

\author{
José Luis Sandoval-Gutiérrez*
}

*Instituto Nacional de Enfermedades Respiratorias Ismael Cosío Villegas, Ciudad de México, México.

Para que pueda ser he de ser otro, Salir de mí, buscarme entre los otros, Los otros que no son si yo no existo, Los otros que me dan plena existencia.

\section{Octavio Paz, Piedra de sol}

Recién sale a luz una publicación que invita al análisis y reflexión de los diferentes problemas contemporáneos en el ejercicio de la profesión médica (Figura 1).

La iniciativa encabezada por el Dr. Jaime Villalba Caloca quien presidio por más de una década el Comité Hospitalario de Bioética del Instituto Nacional de Enfermedades Respiratorias Ismael Cosío Villegas (INER), donde integró a 17 autores de diferentes campos del saber revisando los tópicos de: cuidados paliativos, enfermo terminal, información de la salud, nutrición, relación intercultural, especialidades médicas, encarnizamiento terapéutico, derechos humanos, VIH/SIDA, donación de órganos, atención primaria de salud, médicos residentes y la visión de los pacientes.

\section{Como lo menciona el patrocinador (CHINOIN) de esta edición:}

Difundir ideas que son producto de diálogos, de observaciones, de experiencias y de análisis para tomar decisiones que se circunscriban a la ética, en el vasto campo del ejercicio médico, constituye una aportación, tal vez modesta, pero con la mejor intención de formar parte de

Correspondencia:

Dr. José Luis Sandoval-Gutiérrez

Instituto Nacional de Enfermedades Respiratorias

Ismael Cosío Villegas, Ciudad de México, México.

Correo electrónico: sandovalgutierrez@gmail.com una cadena de comunicación que contribuya a reforzar el interés por ahondar en el estudio del comportamiento de quienes se ocupan de actuar en los distintos planos de las ciencias de la salud.

Los integrantes de este comité acordaron reunir sus reflexiones sobre bioética y publicarlas no sólo como

\section{REFLEXIONES BIDÉTICAS}

Comité

Hospitalario de Bioética

Instituto Nacional de Enfermedades Respiratorias "Ismael Cosío Villegas"

Figura 1: Portada del libro «Reflexiones Bioéticas» Comité Hospitalario de Bioética (INER). 
Neumol Cir Torax. 2020; 79 (1): 59-60

aportación para los ojos interesados en esta área de la medicina, sino también como un reconocimiento y justo homenaje al Doctor Villalba. Las palabras que forman parte de la bioética que se convierten en inicios de análisis para marcar los pasos de un comportamiento médico, cuyo fin es lograr la salud de los pacientes o en determinados casos asumir realmente los mejores cuidados y paliativos que ayuden a controlar y disminuir los sufrimientos y angustias del enfermo y sus familiares.

\section{El Doctor Villalba señala:}

«Estamos aprendiendo a responder preguntas con más preguntas, y a reconocer la importancia de la "otredad" desde la carga simbólica que esto significa; como dice Octavio Paz en este magnífico poema que abre la presente introducción "mirarnos en el otro para poder ser nosotros". Esta perspectiva es una manera muy sana de luchar contra la xenofobia, homofobia, racismo, segre- gación, etcétera, que desafortunadamente en pleno siglo XXI todavía existe. Sin duda la lectura de este libro nos enriquece y nos estimula a continuar en este camino apasionante de la ética como valor fundamental del humanismo en la medicina».

El libro se encuentra en versión electrónica y física, se puede compartir sin ningún costo para al que así lo desee, permitiendo su difusión sin obstáculos a este gran tema del humanismo.

En el futuro se programarán mesas de discusión en los diferentes congresos de medicina principalmente de enfermedades respiratorias y posteriormente donde se convoquen.

Hay una invitación para adentrarse en la búsqueda del otro a través de 12 capítulos en 160 páginas que componen esta publicación, dando un buen motivo para su lectura.

iEnhorabuena! Otoño, 2019, Ciudad de México. 